This item was submitted to Loughborough's Research Repository by the author.

Items in Figshare are protected by copyright, with all rights reserved, unless otherwise indicated.

\title{
Coming out and staying in industry: How sexual orientation and gender identity matters in construction employment
}

PLEASE CITE THE PUBLISHED VERSION

https://doi.org/10.1680/jmuen.17.00026

PUBLISHER

(C) ICE Publishing

VERSION

AM (Accepted Manuscript)

\section{PUBLISHER STATEMENT}

This work is made available according to the conditions of the Creative Commons Attribution-NonCommercialNoDerivatives 4.0 International (CC BY-NC-ND 4.0) licence. Full details of this licence are available at: https://creativecommons.org/licenses/by-nc-nd/4.0/

\section{LICENCE}

CC BY-NC-ND 4.0

\section{REPOSITORY RECORD}

Barnard, Sarah, and Andrew R.J. Dainty. 2019. "Coming Out and Staying in Industry: How Sexual Orientation and Gender Identity Matters in Construction Employment”. figshare. https://hdl.handle.net/2134/28388. 


\section{Coming out and staying in industry: How sexual orientation and gender identity matters in construction employment}

Corresponding Author: Dr Sarah Barnard, School of Business and Economics, Loughborough University (Tel: 01509223100 Email: S.H.Barnard@lboro.ac.uk) and Professor Andrew Dainty, School of Civil and Building Engineering, Loughborough University

To cite: Barnard, S., \& Dainty, A. (2017, November). Coming out and staying in industry: How sexual orientation and gender identity matters in construction employment. In Proceedings of the Institution of Civil Engineers-Municipal Engineer (pp. 1-24). Thomas Telford Ltd.

Over the last three years the New Civil Engineer, Architects' Journal and Construction News have conducted a survey investigating the experiences of LGBT workers in the sector. The surveys reveal that homophobia is commonplace in the construction industry, with many gay men and women encountering homophobic comments in the workplace and few feeling that they could be open about their sexuality in the workplace (Ramchurn, 2015a; 2015b). Furthermore, respondents had little faith that their managers would handle such issues effectively. In this literature review paper we explore the theoretical and empirical explanations for the apparent institutionally homophobic situation of the sector. A key concern is what are the experiences of LGBT people and in what ways does gender/sexual identity present challenges in working lives? The results reveal the importance of sexuality in the reproduction of social relations in construction, the nature of sexualised banter and physical harassment of LGBT workers and the effects that this has on equality of opportunity. The cultural landscape represents a toxic environment for those who do not conform to the white, male, heterosexual stereotype of the construction worker and the homosocial relations that surround it. Furthermore, the review highlights how research has evolved to now present a critical perspective on how gender and sexualities are performed in organizational contexts (Rumens, 2013). The results presented set the agenda for empirical explorations of the experiences of workers. The main contribution of the paper is that it begins to unpack the institutional landscape that sustains the status quo and which must be challenged if more inclusive practices are to take hold within the sector.

Keywords: Construction, Equality and Diversity, Sexuality, LGBT, Inclusion, Career

\section{Introduction}

The construction sector is generally not thought of as a bastion of progressive identity politics.

Recurrent and ongoing drives to promote more diversity in the sector might be considered mere 'tinkering at the edges' of a culture that dismisses and diminishes individuals or groups of people who do not fit stereotypical norms of construction workers. The non-inclusive 
culture may not just be an issue for minorities: the Office for National Statistics have recently published data that shows that low skilled male construction workers have the highest risk for suicide in the UK, which is 3.7 times above the national average (ONS, 2017; see also The Guardian, 2017). Whilst the ONS (2017) acknowledge low pay and low job security among other factors that contribute to elevated risk that are relevant to the construction sector, broader cultural aspects are not explicitly mentioned. The idea of a toxic culture potentially impacting all employees should not be dismissed out of hand. It is in this broader context that we highlight the need to hear the voices of minorities in the sector and also as a way of exploring the complex relationships between working cultures, individual career experiences and potentialities for greater equality in organisations.

The need for a more inclusive culture is a broadly acceptable premise for a sector looking to recruit employees in a competitive market. Although there has been a sustained focus in recent years on understanding the experiences of underrepresented groups in construction such as women and minority ethnic workers, there has been a paucity of work which has explored the experiences of lesbian, gay, bisexual and transgender (LGBT) workers within the industry. This trend reflects also the relative lack of interest in LGBT issues from an organisational perspective (Ng \& Rumens, 2017; Anteby \& Anderson, 2014) or in relation to other dimensions of diversity (Ng \& Rumens, 2017). Although it is difficult to establish the precise number of people working in construction given high levels of selfemployment/casual labour and the nebulousness of what defines the sectors boundaries (Pearce, 2003), construction currently employs around 10\% of the UK's working population or 3 million people (Telegraph 2017). According to Construction Industry Council’s Diversity Report (2015: 6) 0.2 per cent of employees surveyed identified as lesbian, 0.8 per cent as gay and 1.0 per cent at bisexual. Whilst LGBT workers are in a minority in the sector, 
the negative experiences of this group should not be overlooked. An annual survey collaboratively conducted by New Civil Engineer, Architect's Journal and Construction News (survey respondents $n=1000$ in 2015, n=1403 in 2016 and n=1400 in 2017) revealed that homophobia is commonplace in the construction industry; many gay men and women had encountered homophobic comments in the workplace and a small minority of gay employees felt that they could be open about their sexuality (Ramchurn, 2015a; Hansford, 2017) - a situation that mirrors findings of an earlier survey conducted by the Institute of Engineering and Technology (2014). That this is the situation in the UK context where protective legislation is argued to be progressive compared to many other countries (Beauregard et al., 2016: 19) highlights the chasm between a top-down, organisational policy level engagement with diversity issues and what happens 'on the ground' (Colgan et al., 2007). As an important starting point for an empirical investigation, this paper reviews the research that has focus in particular on LGBT in construction and the broader literature of LGBT in organizations. This literature explores the experiences of LGBT workers and feeds into an understanding of how sexual orientation and gender identity matters in construction employment. In doing so it begins to attend to the lack of focus on within-gender diversity research highlighted by Rumens (2013) and the need to examine alternative forms of masculinity within construction discussed by Chan (2013).

This review draws on the literature on LGBT in construction and on sexual orientation in organisational research more broadly to explore current understandings of the issue. Literature based on empirical data was identified through research databases (e.g. SCOPUS) and filtered on the basis of relevance to the topic. In addition to database searching the literature that informs relevant review studies on LGBT in organisations have also been checked through and drawn on for this analysis: in particular Ng et al. (2017); Anteby et al. 
(2014); Caplan et al. (2009); Badgett et al. (2013), Phoenix and Ghul (2016) and McFadden (2015).

The relatively few studies that focus specifically on LGBT construction sector (see Chan 2011; 2013; Denissen \& Saguy 2010; Frank, 2001; Wright, 2011, 2013; Riley, 2008; Ramchurn, 2015a, Rumens 2013) are analysed in the context of a greater body of work on equality and diversity in construction and the experiences of LGBT employees in the workplace and organisational approaches towards equality practices. The empirical studies explicitly focused on the construction sector have been on lesbians (Denissen \& Saguy 2010; Frank, 2001; Wright, 2011, 2013), homosexual men (Chan, 2011), and non-heterosexuals (Chan, 2013; Ramchurn, 2015a). Two of the papers do not draw directly from empirical data: Rumens’ (2013) paper aon men and masculinities in the sector and Riley’s (2008) paper focuses on LGBT in engineering. What is significant here is that there has not been an empirical study on transgender people in construction to date. Therefore the literature on transgender for this review paper is drawn from relevant research from other sectors. The key questions for the review to answer are what are the experiences of LGBT people in their working lives and in what ways does gender/sexual identity present challenges to career. This work is significant because it will broaden the diversity agenda to consider the nuances of the range of experiences across those identifying as LGBT. The construction sector is increasingly attempting to address inclusion, and studies such as this will feed into that agenda. 


\section{Diversity in the construction sector}

The lack of diversity in the construction sector, particularly with regards to women, is now well documented in the literature (Ness, 2012). There have been a wide range of studies looking at education routes of women into the industry (Alpay, 2013; Barnard et al., 2012), career choice, occupational or contractual gender segregation in the sector (Powell et al., 2012; Gayani Fernando et al., 2014; Olofsdotter \& Rasmusson, 2016), and the leaky pipeline in the engineering profession (Faulkner, 2009). Moving away from a 'fix the women' agenda evident in some literature on the topic (Vries et al., 2006; Barnard et al., 2009; Ness, 2012), Worrall et al.’s (2010) study found that in the UK construction industry male-dominated organisational cultures and inflexible working practices are the main barriers to women. Similarly, writing from an Australian perspective, French and Strachan (2015) argue that the construction sector is not engaging with equal employment issues. They suggest that where women are entering and being successful in the sector this is based on individual choice rather than commitment to equality in diversity from construction organizations per se.

Overall this strand of research demonstrates and responds to the overwhelming overrepresentation of men in the construction sector. The white, male, heterosexual stereotype of the construction worker and the homosocial (same-sex, usually men) relations that surround it are a key feature of issues that minorities face in the industry. Over the past few years a number of studies have emerged which have begun to question the dominant essentialist (i.e. gender differences are fundamentally inherent) view on men and masculinities in construction through the mobilisation of critical theory (Chan 2013, Rumens 2013). Rumens, for example, suggests that there has been an absence of discussion about masculinities and femininities within the construction management literature. Queer theory in particular, Rumens argues, offers a powerful critique of the heteronormative taken-for- 
granted aspects of everyday life as it highlights the ways in which cultures and institutional structures privilege and normalise heterosexuality. Queer theory allows for the questioning of traditional stable gender categories, thereby opening up social relations for investigation (Chan 2013).

\section{LGBT in the construction sector and organizational research}

Within the equality and diversity field work around LGBT may be considered more complex in the sense that sexuality and gender identity is not necessarily something that is public or identifiable as such, rather ‘a concealable identity’ (Ng \& Rumens, 2017: 110). Beauregard et al. (2016) go further and suggest that LGB people in particular may face issues around invisible stigma disclosure, whereby people face discrimination in response to being open about their sexuality. Related to this it has been recognised that there are difficulties finding reliable, sector-specific data on LGBT workers (Ng \& Rumens, 2017). However, the complexity of taking into account sexual orientation or gender identity should not be used as an excuse for non-engagement with these minorities. Writing in 2008, Aspinall and Mitton suggest that 'the lack of data sources on sexual orientation is now conspicuous' (2008: 66). Despite raising these concerns, Aspinall and Mitton (2008) go on to acknowledge potential impacts of the limited capacity that organisations may have to collect and analyse the range of data around the different equality strands. There is also a minority of people who do not neatly fit into the gender/sexual orientation categories on offer on administrative forms instead appearing as ‘something else' and therefore represent a challenge for data analysis (Eliason et al., 2016). The figures provided by the Construction Industry Council’s Diversity Report (2015: 6) show a percentage of 2\% LGB in the sector. However, it should also be taken into account that data like these tend to underestimate the number of non-heterosexual 
people in the population (Coffman et al., 2016). The particular situation of the construction sector - male dominated, often project based, mobile working practices - in addition to the prevalence of gender stereotypes and particular forms of masculinities suggests that this context may be particularly problematic for minorities (Chan, 2013).

The collection and analysis of data on LGBT workers might be considered the starting point for a more nuanced discussion of the varied experiences of minorities in the workplace. This paper does not suggest that the grouping together of sexual and gender minorities precludes a sensitive consideration of the differences within LGBT or between lesbians, gay men, bisexual or transgender people. Broadly, we might consider that foregrounding the experiences of LGBT employees as a group might help tackle issues around heteronormativity that is considered pervasive in the literature on work post 1990s ( $\mathrm{Ng} \&$ Rumens, 2017). Furthermore, the norms around sexuality and heteronormativity have implications for homosexual and heterosexual employees as these are often grounded in essentialist ideas around the role of men and women in society and the unproblematic alignment of gender and sex identity.

A common theme in the literature is the way LGBT people contest the idea that gender and sex identities simply overlap and are fixed. Research on lesbians in construction is a way for the intersection of sexuality and gender to be explored empirically, also recognising that women represent a small proportion of the construction workforce. Frank (2001) puts forward the idea that lesbians through their sexuality challenge the status quo, therefore challenging gender roles by going into the trades is an extension of this rejection of societal norms. This is a compelling argument considering the research by Tilcsik et al. (2015) which shows that gay men are more likely to be in female-majority occupations than are 
heterosexual men, and lesbians are more represented in male-majority occupations than are heterosexual women. However, research has also shown that being in a sexual orientation and gender minority may consolidate exclusion in the workplace, what Hall (1989) terms the double jeopardy of lesbians. The intersection of sexuality and gender is a crucial issue in a discussion of LGBT as Wright (2011) argues that studies on sexual minorities should be aware of the gender dimension, as lesbians and gay men may experience working contexts in differing ways. In fact, Hall (1989) suggests that lesbians find gender more of an issue than sexuality in the workplace. This highlights that the experiences of lesbians in construction may differ significantly from those of gay men and the differential-gendered outcomes of homophobia should be properly recognised.

Taking into account the differences between LGBT employees, there is a body of work that has focused in particular on bisexual workers in organisations. Köllen (2013) argues that there is a need for workplaces to properly acknowledge and support bisexual workers as a distinct group from gay or lesbians. This suggests that the particular experiences of bisexual people differs, some suggesting that they experience the ‘double discrimination' of homophobia and biphobia (Colledge et al., 2015). Bisexual people can be described to experience exclusion from both heterosexual and homosexual colleagues. In a survey study on the mental health of women, Colledge et al. (2015) found mental health issues and psychological distress to be greater for bisexual women than lesbians. Despite findings like these, bisexual workers are not recognised or tend to have a lower profile in organisational support and networks than lesbian or gay people: research by Green et al. (2011) shows that workplaces in general do not offer specific support or events for bisexual workers. This suggests that as construction companies develop LGBT engagement there should be 
consideration of the different perspectives that lesbian, gay, bisexual and transgender represent and engagement activities that reflect these differences.

\section{Coming out}

A key theme in the literature on LGBT employees in construction and in organisations more generally is with regards to the question of concealing or revealing sexual orientation coming or being out. In some ways this is a distinguishing factor for LGBT workers in comparison with gender or ethnic minorities that have been more frequently focused on in construction research (Wright, 2016: 34). As there has not been a systematic quantitative study on sexual minorities in the sector it is not clear what proportion are out at work. Ramchurn’s (2015a; 2015b) and Hansford's (2016; 2017) reports on research in the sector showed between 8 and14 per cent of gay employees felt that they could be open about their sexuality in contracting roles, which suggests that between 86 and 92 percent are not comfortable with their sexuality being known.

The nature of the disclosure is also an interesting aspect of research in that the metaphor of 'coming out of the closet' does not capture the experience of LGB people, who describe it not as a one-off event, but rather an on-going process, where repeated disclosures are made necessary in new contexts and with new colleagues (Wright, 2016; Ward \& Winstanley, 2005). Therefore, being 'out' or 'coming out' falls along a continuum of: concealment, select colleagues knowing, to fully being out (Wright, 2016; Ragins \& Cornwell, 2001; Miller, 2003), which also changes over time. Overall sexual minorities make decisions about coming out partly in response to the organisational context and how they assess what Hall (1989: 129-132) terms the danger of disclosure versus dangers of non-disclosure - meaning that there are risks associated with either option. The risks associated with coming out are with 
regards to facing discrimination and homophobia, which manifests in various guises depending on the context. For example, Miller's (2003) study on lesbians and gay men in the police found that one of the reasons for not coming out was the perception of risk of physical harm should their colleagues not back them up as a result of homophobia. All the studies in the construction sector identified instances of homophobia, occurring in contact with clients (Chan, 2013) or with colleagues (Wright, 2013). Worryingly there is evidence of discrimination subsequent to individuals' coming out, masked through the guise of performance assessment (Chan, 2013).

As Hall (1989) highlights, non-disclosure also has risks with regards to one’s identity and psychological well-being. 'Outness' is also associated with greater levels of job/life satisfaction (Huffman et al., 2008). There are some studies that suggest that coming out has further positive impacts. LGBT women in the technology sector reported greater sense of belonging, perceived as more competent and avoided some discrimination that heterosexual women in the sector experience as a result of coming out (Alfrey \& Twine, 2017). Wright's (2011) study also found that out lesbians in construction experienced less unwanted attention as a result of coming out. Therefore the impact of coming out on work experiences is varied.

The complexity of disclosure is amplified further with regards to transgender people as the idea of coming out has different implications for transpeople than for LGB (Beauregard et al., 2016). Beauregard et al.’s (2016) study found that there is a tension between those who wish to keep their transition private with those who wish to actively want to be heard and known as trans (Beauregard et al., 2016). Not being an out transperson means they can live as an authentic person, whereas for LGB coming out increases identity integration (Beauregard et al., 2016). The study also found evidence of discrimination and abuse of transpeople 
(Beauregard et al., 2016), meaning that disclosing transgender identity could be considered an unappealing option for many transgender people. As there have not been any studies of transgender people in construction it is not possible to consider the specificities of employees in the sector, however, it is likely that some of the aspects raised in Beauregard's (2016) study are salient.

\section{Staying in}

Research on the experiences of sexual and gender minorities in their day-to-day working lives highlight contradictory discourses around visibility and the public/private divide of sexuality. Chan's $(2011 ; 2013)$ research on gay men and non-heterosexuals in construction in the UK argues that sexuality is an important factor in the reproduction of social relations in construction. Homosexuality is framed as a private matter, unlike heterosexuality, which is normalised through social interactions (see also: Riley, 2008; Wright, 2013). There is also the potential for exclusion on the basis of minority gender and minority sexuality status, for example missing out on work gossip or not being invited to social gatherings (Miller, 2003). Despite this disavowal of non-heterosexual forms of sexuality, those who are out in the sector are more visible. Wright (2016) and Bilimoria and Stewart (2009) found that LGBT workers faced higher levels of scrutiny, which is in line with earlier work by Kanter (1977) which shows that minorities are constantly scrutinized by their colleagues.

In addition to higher levels of exclusion and scrutiny, harassment and negative experiences are widely reported by LGBT people. Wright (2013; 2016) carried out interviews with heterosexual women and lesbians in construction. The research found evidence of sexualised banter and physical harassment that is perceived to be tolerated less in other sectors. Some interviewees in Wright's (2016) study reported a reduction in sexual tension in workplace 
relations, although flirting continued to be a feature of interactions with colleagues. Cech et al.’s (2017) study on LGBT workers in STEM organizations found that LGBT employees report systematically more negative workplace experiences than their non-LGBT colleagues, regardless of gender, age or status in the hierarchy. Even though harassment and negative experiences are commonplace, it is argued that construction employers are less experienced or effective in their response to homophobic harassment than other forms of harassment (Wright, 2013). The combination of higher levels of harassment and weaker organisational response represents a difficult situation for those wishing to stay in the construction industry.

The negative outlook can be tempered by acknowledging the agency of LGBT employees in managing what appear to be challenging working environments. Studies of lesbians illustrate how gender is a key factor in understanding how sexuality plays out in organizations. Hall (1989) acknowledges the complexity of the situation of managing gender for lesbians, in much the same way as Denissen (2010) describes how tradeswomen reflexively adjust gender performances depending on the situation. The women here describe how this is not a static situation, and gender is managed and performed through on-going interactions with managers, colleagues, or clients. Other mechanisms for coping with negative impacts of minority status is outlined by Chan (2013) who found examples of minorities countering exclusionary forms of masculinity through 'friendship’ alliances at work. Both the mechanisms described gender performance and managing relationships with colleagues - highlight the significance of social skills for LGBT people wishing to be out and stay in the sector.

\section{Consequences for careers in construction}

LGBT employees facing harassment at work who experience the associated personal impacts on working relationships, mental health and well-being also face real consequences for their 
careers. Bilimoria and Stewart (2009) have importantly made a connection between negative experiences of LGBT employees in science and engineering academia and consequences for career. In particular the role pressures and choices they face, and the effects of the climate on their work performance and careers. Research has shown that people may face job security issues, impacts on promotion prospects, which is related to bosses and colleagues' homophobic attitudes (Hall, 1989). Riley (2008) suggests that construction workers themselves are not necessarily homophobic but that it is the heteronormative culture in construction that is most problematic, an issue also highlighted by Chan (2013). The overall situation with regards to homophobic attitudes and their potential impacts on careers is not clear. On the one hand, there appears to be positive progress in workplaces with regards to sexual orientation discrimination (Correia \& Kleiner, 2001), and on the other hand, studies have found that found that anti-gay sentiments in workplace settings are stronger and more prevalent than expected (Coffman et al., 2016). Perhaps this situation can be likened to the move from overt to covert sexism that women have experienced in the workplace? In the face of homophobia and discrimination LGBT employees say that they want and need inclusion, safety, and equity (Brooks \& Edwards, 2009). What is clear is that LGBT workers face challenges with regards to both sexuality and gender in negotiating a career in construction and the industry has a key role to play in supporting (and duty of care for) all their employees.

Researchers in LGBT in organizations and construction specifically have made suggestions of rationales for action and considerations to be taken into account. The politics of the diversity agenda that has focused, and continues to focus with good reason, on the experiences of women in construction has now broadened in the larger organisations to include LGBT issues. It has been suggested that the next steps are for both large and small construction companies to engage with LGBT diversity (Riley, 2008), this engagement 
should be proactive and connected to broader concerns around social responsibility (Colgan et al., 2007). The 'implementation gap’ identified between equality and diversity policy and practice on sexual orientation (Colgan et al., 2007) suggests that the main concern here is that industry should be actively engaging rather than coming up with new policies. Cook and Glass (2016) suggest that involving younger members of staff on boards may help with advancement of LGBT policies, though Everly and Schwarz (2015) have conversely found that this may not be the case. Riley (2008) states that construction sector should go beyond formal policy formation to actively foster LGBT-friendly environments (diversity training, LGBT networks e.g.). Some companies have been doing just that. For example, the InterEngineering LGBT Network (Construction Industry Council, 2015: 16) or the Construction Industry Training Board (CITB) project aimed at addressing stereotyping of LGB apprentices in construction carried out by the Equality Challenge Unit. It is suggest that actions like these help to create a more open climate in which LGBT employees can feel comfortable and supported.

In addition to setting up networks, it is crucial for HR professionals, line managers and senior management to recognise and support LGBT employees. Training of HR staff around transgender is argued to be crucial as they are often the first point of contact about gender transitions (Davis, 2009). At a management level, Huffman et al. (2008) found that higher levels of supervisor support for LGB employees was related to greater job satisfaction, coworker support was related to life satisfaction, and organisational support for LGB employees was related to out-ness. A relationship between managerial support for gay and lesbian workers and job satisfaction was also found in Day and Schoenrade’s (2000) study. Overall supportive practices for sexual minorities are recognised as being partially effective: survey research in Switzerland (Lloren \& Parini, 2016) found that supportive diversity management 
policies contributes to shaping the experience of LGB employees by reducing discrimination and increasing overall well-being at work, although psychological health was less effected.

There is also scope for a holistic look at diversity as a whole. For example, it is interesting to consider research on the relationship between gender diversity and policies relating to LGBT. Cook and Glass (2016) found that Fortune 500 firms in the USA with gender- diverse boards are more likely than other firms to offer LGBT-friendly policies (however, findings for firms with women CEOs offer mixed results). Everly and Schwarz (2015) have also found a relationship between gender diversity more broadly and company policies towards LGBT. In addition, LGBT supportive policies are linked to positive outcomes for minorities as well as for the business (Badgett et al., 2013). Therefore, research suggests that the policy-practice climate around LGBT in organisations is related to the situation of other minorities. This strongly suggests that the situation for sexual orientation or gender minorities should not be viewed in isolation and that a broad perspective on diversity is paramount (Pichler et al., 2017).

\section{Conclusions: Evolution of LGBT research and future agendas}

The literature reviewed for this paper outlines that ways in in which sexual and gender identity matter to those who work in organisations and in the construction sector, in particular. Decisions about disclosure of identity are an on-going, day to day issue for LGBT workers, and experiences of homophobia in the workplace have significant impacts at both personal and professional levels. As minorities in the workplace, the experiences of lesbians, gay men, bisexual and transgender employees vary significantly, and the issues that people face at work differ according to their particular circumstances. An additional purpose of this paper is 
to consider the ways in which the research agenda has evolved over time, and the residual gaps that remain. As we have explored the situation of LGBT in construction in relation to coming out, staying in and consequences for career we can also identify three distinct generations of research on diversity and equality: $1^{\text {st }}$ wave Studies looking at underrepresented groups to plug skills gaps; $2^{\text {nd }}$ wave research driven by a need to improve the experience of minority groups of working in the industry (structurally and culturally); and the latest more critical generation which look to question taken-for-granted and essentialist assumptions around heteronormative cultures.

With the third comes a new set of critical theories which allow for the deeper interrogation of how genders and sexualities are performed. That LGBT experiences become areas of focus is no surprise within such studies, but the important thing is that they begin to question traditional notions of power and the very institutions which have maintained the rather deterministic first and second generation views. In this way the latest work represents a radical departure for addressing so much of what maintains the current stasis in the industry. Thus, while LGBT are a small constituency, the study of gender performativity that their consideration requires promises much in terms of challenging understandings of the sector and its workplace climate.

In-depth research on the experiences of such workers and the effectiveness of policies and actions to address these issues is vital if the sector is to begin to tackle these issues and to benefit from the advantages that a more representational workforce provides. Further research should explore academic contributions through the application of LGBT theory to the uniquely complex context of the construction industry, and practical benefits in the form of practicable recommendations for ensuring the inclusivity of employment practices. There is a 
need for more research on transgender people at work (Beauregard et al., 2016), sexual orientation in organisations (Anteby \& Anderson, 2014;), particularly building on the themes identified by McFadden (2015) and the research questions identified by Rumens (2013), around career or identity overlap, organizational and human resources perspectives, discrimination Identity, and social issues and experiences. The next stage of our study will fill a significant gap in the research landscape on equality and diversity in the construction sector as well as providing the first significant insights into the experiences of this less heard constituency.

\section{References}

Alpay, E. (2013). Student attraction to engineering through flexibility and breadth in the curriculum. European Journal of Engineering Education, 38(1), 58-69. http://doi.org/10.1080/03043797.2012.742870

Anteby, M., \& Anderson, C. (2014). The shifting landscape of LGBT organizational research. Research in Organizational Behavior, 34, 3-25. http://doi.org/10.1016/j.riob.2014.08.001

Alfrey, L., \& Twine, F. W. (2017). Gender-Fluid Geek Girls: negotiating inequality regimes in the Tech industry. Gender \& Society, 31(1), 28-50.

Aspinall, P. J., \& Mitton, L. (2008). "Kinds of people” and equality monitoring in the UK. Policy \& Politics, 36(1), 55-74.

Badgett, M. V. L., Durso, L. E., Mallory, C., \& Kastanis, A. (2013). The Business Impact of LGBT-Supportive Workplace Policies. Retrieved from https://escholarship.org/uc/item/3vt6t9zx

Barnard, S., A. Powell, B. Bagilhole, and A. Dainty. 2009. "Researching UK Women Professionals in SET: A Critical Review of Current Approaches." Gender, Science and Technology 2 (3): 361-81.

Barnard, S., et al., 2012. 'They're not girly girls': an exploration of quantitative and qualitative data on engineering and gender in higher education. European Journal of Engineering Education, 37, 193-204.

Beauregard, T.A., Arevshatian, L., Booth, J. E., \& Whittle, S. (2016). Listen carefully: transgender voices in the workplace. The International Journal of Human Resource Management. http://doi.org/10.1080/09585192.2016.1234503

Bilimoria, D., \& Stewart, A. J. (2009). “Don”t Ask, Don’t Tell’: The Academic Climate for Lesbian, Gay Bisexual and Transgender Faculty in Science and Engineering. NWSA Journal, 21(2), 85-103. http://doi.org/10.1353/nwsa.0.0077

Brooks, A. K., \& Edwards, K. (2009). Allies in the Workplace: Including LGBT in HRD. Advances in Developing Human Resources, 11(1), 136-149. http://doi.org/10.1177/1523422308328500

Caplan, A., Aujla, A., Prosser, S., \& Jackson, J. (2009). Race Discrimination in the 
Construction Industry: a thematic review. Retrieved from http://195.224.14.164/uploaded_files/download_race_inquiry_thematic_review.pdf

Cech, E. A., Pham, M. V, Charles, M., \& Thébaud, S. (2017). Queer in STEM Organizations: Workplace Disadvantages for LGBT Employees in STEM Related Federal Agencies. http://doi.org/10.3390/socsci6010012

Chan, P. W. (2011). Queer ( Y ) Ing Construction : Exploring Sexuality and Masculinity in Construction, (September), 207-216.

Chan, P. W. (2013). Queer eye on a "straight” life: deconstructing masculinities in construction. Construction Management and Economics, 31(8), 816-831. http://doi.org/10.1080/01446193.2013.832028

Coffman, K. B., Coffman, L. C., \& Ericson, K. M. M. (2016). The Size of the LGBT Population and the Magnitude of Antigay Sentiment Are Substantially Underestimated. Management Science. http://doi.org/10.1287/mnsc.2016.2503

Colgan, F. (2011). Equality, diversity and corporate responsibility: Sexual orientation and diversity management in the UK private sector. Equality, Diversity and Inclusion: An International Journal, 30(4), 719-734. Retrieved from https://doi.org/10.1108/02610151111183225

Colgan, F., Creegan, C., McKearney, A., \& Wright, T. (2007). Equality and diversity policies and practices at work: lesbian, gay and bisexual workers. Equal Opportunities International, 26(6), 590-609. http://doi.org/10.1108/02610150710777060

Colgan, F., \& McKearney, A. (2012). Visibility and voice in organisations: Lesbian, gay, bisexual and transgendered employee networks. Equality, Diversity and Inclusion: An International Journal, 31, 359-378

Colledge, L., Hickson, F., Reid, D., \& Weatherburn, P. (2015). Poorer mental health in UK bisexual women than lesbians: evidence from the UK 2007 Stonewall Women's Health Survey. Journal of Public Health (Oxford, England), 37(3), 427-437. http://doi.org/10.1093/pubmed/fdu105

Construction Industry Council. (2015). A Blueprint for change? Measuring Success and Sharing Good Practice. Construction Industry Council Diversity Report.

Cook, A., \& Glass, C. (2016). Do women advance equity? The effect of gender leadership composition on LGBT-friendly policies in American firms. Human Relations, 2-26. http://doi.org/10.1177/0018726715611734

Correia, N., \& Kleiner, B. H. (2001). New developments concerning sexual orientation discrimination and harassment. International Journal of Sociology and Social Policy, 21(6), 92-100. Retrieved from https://doi.org/10.1108/01443330110789844

Davis, D. (2009). Transgender Issues in the Workplace: HRD's Newest Challenge/Opportunity. Advances in Developing Human Resources, 11(1), 109-120. http://doi.org/10.1177/1523422308329189

Day, N. E., \& Schoenrade, P. (2000). The relationship among reported disclosure of sexual orientation, anti-discrimination policies, top management support and work attitudes of gay and lesbian employees. Personnel Review, 29(3), 346-363. http://doi.org/10.1108/00483480010324706

Denissen, A. M. (2010). The right tools for the job: Constructing gender meanings and identities in the male-dominated building trades. Human Relations, 63(7), 1051-1069. http://doi.org/10.1177/0018726709349922

Denissen, A.M. and Saguy, A.C. (2010) 'I'm not free porn': lesbian tradeswomen and the contradictions of workplace discrimination. Working Paper for the UCIA Williams Institute.

Eliason, M., Radix, A., McElroy, J., Garbers, S., \& Haynes, S. (2016). The "Something Else” of Sexual Orientation: Measuring Sexual Identities of Older Lesbian and Bisexual 
Women Using National Health Interview Survey Questions. Women's Health Issues :, 26(1), S71-S80. http://doi.org/10.1016/j.whi.2016.03.012

Everly, B. A., \& Schwarz, J. L. (2015). Predictors of the adoption of LGBT-Friendly HR policies. Human Resource Management, 54(2), 367-384.

http://doi.org/10.1002/hrm.21622

Faulkner, W. (2009). Doing gender in engineering workplace cultures. II. Gender in/authenticity and the in/visibility paradox. Engineering Studies, 1(3), 169-189. http://doi.org/10.1080/19378620903225059

Fidas, D., Cooper, L., \& Raspanti, J. (2015). The cost of the closet and the rewards of inclusion: why the workplace environment for LGBT people matters to employees. Human Rights Campaign, 4-5.

Frank, M. (2001) Hard hatted women: lesbians in the building trades. New Labor Forum, 8(8), 25-36.

French, E. \& Strachan, G. (2015). Women at work! Evaluating equal employment policies and outcomes in construction. Equality, Diversity and Inclusion: An International Journal, 34(3), 227-243. http://doi.org/10.1108/EDI-11-2013-0098

Gates, G. J. (2011). How many people are lesbian, gay, bisexual, and transgender?

Gayani Fernando, N., Amaratunga, D., \& Haigh, R. (2014). The career advancement of the professional women in the UK construction industry. Journal of Engineering, Design and Technology, 12(1), 53-70. http://doi.org/10.1108/JEDT-04-2012-0018

Green, H. B., Payne, N. R., \& Green, J. (2011). Working Bi: Preliminary Findings from a Survey on Workplace Experiences of Bisexual People. Journal of Bisexuality, 11(2-3), 300-316. http://doi.org/10.1080/15299716.2011.572007

The Guardian (2017) 'Male construction workers at greatest risk of suicide, study finds', published 17 March 2017. Available at:

https://www.theguardian.com/society/2017/mar/17/male-construction-workers-greatestrisk-suicide-england-study-finds Accessed: 23/6/17.

Hansford, M. (2016). Sustained Prejudice. New Civil Engineer, $8^{\text {th }}$ November 2016. Retrieved from https://www.newcivilengineer.com/business-culture/equality-surveysustained-

prejudice/10014569.article?search=https\%3A\%2F\%2Fwww.newcivilengineer.com\%2F searcharticles\%3Fqsearch\%3D1\%26keywords\%3DLGBT+survey

Hansford, M. (2017, September). Attitudes to LGBT+ in construction | third annual survey. New Civil Engineer, $4^{\text {th }}$ September 2017. Retrieved from

https://www.newcivilengineer.com/business-culture/attitudes-to-lgbt-in-constructionthird-annual-survey/10023110.article

Huffman, A. H., Watrous-Rodriguez, K. M., \& King, E. B. (2008). Supporting a diverse workforce: What type of support is most meaningful for lesbian and gay employees? Human Resource Management, 47(2), 237-253. http://doi.org/10.1002/hrm.20210

Ineson, E. M., Yap, M. H. T., \& Whiting, G. (2013). Sexual discrimination and harassment in the hospitality industry. International Journal of Hospitality Management, 35, 1-9. http://doi.org/10.1016/j.ijhm.2013.04.012

Institute of Engineering and Technology (2014) Many gay engineers still fear "coming out" at work. $21^{\text {st }}$ June 2014. Retrieved from http://www.theiet.org/policy/media/pressreleases/20140721.cfm

Kanter, R.M. (1977), Men and Women of the Corporation, Basic Books, New York, NY.

Köllen, T. (2013). Bisexuality and Diversity Management-Addressing the B in LGBT as a Relevant "Sexual Orientation" in the Workplace. Journal of Bisexuality, 13(1), 122-137. http://doi.org/10.1080/15299716.2013.755728

Lloren, A., \& Parini, L. (2016). How LGBT-Supportive Workplace Policies Shape the 
Experience of Lesbian, Gay Men, and Bisexual Employees. Sexuality Research and Social Policy. http://doi.org/10.1007/s13178-016-0253-x

McFadden, C. (2015). Lesbian, Gay, Bisexual, and Transgender Careers and Human Resource Development. Human Resource Development Review, 14(2), 125-162. http://doi.org/10.1177/1534484314549456

Miller, S. L. (2003). Diversity in Blue: Lesbian and Gay Police Officers in a Masculine Occupation. Men and Masculinities, 5(4), 355-385. http://doi.org/10.1177/0095399702250841

Ness, K. (2012). Constructing masculinity in the building trades: 'Most jobs in the construction industry can be done by women’. Gender, Work \& Organization, 19(6), 654-676.

Ng, E. S., \& Rumens, N. (2017). Diversity and inclusion for LGBT workers: Current issues and new horizons for research. Canadian Journal of Administrative Sciences / Revue Canadienne Des Sciences de l'Administration, 34(2), 109-120. http://doi.org/10.1002/cjas.1443

Office for National Statistics (2017) 'Suicide by occupation, England: 2011 to 2015' Available at: https://www.ons.gov.uk/peoplepopulationandcommunity/birthsdeathsandmarriages/deat hs/articles/suicidebyoccupation/england2011to2015\#main-points Accessed: 23/6/17.

Olofsdotter, G., \& Rasmusson, M. (2016). Gender ( in ) equality contested: externalising employment in the construction industry. New Technology, Work and Employment, 31(1), 41-57.

Pearce, D. 2003. The Social and Economic Value of Construction: The Construction Industry's Contribution to Sustainable Development, London: nCRISP.

Phoenix, N., \& Ghul, R. (2016). Gender transition in the workplace: An occupational therapy perspective. Work, 55(1), 197-205. Retrieved from http://content.iospress.com/articles/work/wor2386

Pichler, S., Ruggs, E., \& Trau, R. (2017). Worker outcomes of LGBT-supportive policies: a cross-level model. Equality, Diversity and Inclusion: An International Journal, 36(1), 17-32. Retrieved from https://doi.org/10.1108/EDI-07-2016-0058

Powell, A., Dainty, A., \& Bagilhole, B. (2012). Gender stereotypes among women engineering and technology students in the UK: lessons from career choice narratives. European Journal of Engineering Education, 37(6), 541-556.

Ragins, B. R., \& Cornwell, J. M. (2001). Pink triangles: antecedents and consequences of perceived workplace discrimination against gay and lesbian employees. Journal of applied psychology, 86(6), 1244.

Ramchurn, R. (2015). Survey results: Homophobia remains rife in construction industry. Architect's Journal, 24 August 2015. Available at http://www.architectsjournal.co.uk/home/survey-results-homophobia-remains-rife-inconstruction-industry/8687957.fullarticle

Ramchurn, R. (2015b) Survey lifts lid on homophobia in the sector. New Civil Engineer, 24 August 2015. Available at: https://www.newcivilengineer.com/business-culture/surveylifts-lid-on-homophobia-in-thesector/8687868.article?search=https\%3a\%2f\%2fwww.newcivilengineer.com\%2fsearcha rticles\%3fparametrics\%3d\%26keywords\%3dLGBT\%26PageSize\%3d10\%26cmd\%3dG oToPage\%26val\%3d3\%26SortOrder\%3d1

Riley, D. (2008). LGBT-Friendly Workplaces in Engineering. Leadership and Management in Engineering, 8(1), 19-23. http://doi.org/10.1061/(ASCE)1532-6748(2008)8:1(19)

Rumens, N. (2013). Queering men and masculinities in construction: towards a research agenda. Construction Management and Economics, 31(8), 802-815. 
http://doi.org/10.1080/01446193.2013.765021

Schilt, K., \& Wiswall, M. (2008). Before and after: Gender transitions, human capital, and workplace experiences. B. E. Journal of Economic Analysis \& Policy, 8, 1-26.

Telegraph (2017) UK Construction Industry. Available at https://jobs.telegraph.co.uk/article/uk-construction-industry/. Accessed 7 July 2017.

Tilcsik, A., Anteby, M., \& Knight, C. R. (2015). Concealable Stigma and Occupational Segregation. Administrative Science Quarterly, 60(3), 446-481. http://doi.org/10.1177/0001839215576401

Vries, J. De, Webb, C., \& Eveline, J. (2006). Mentoring for gender equality and organisational change. Employee Relations, 28(6), 573-587. http://doi.org/10.1108/01425450610704506

Ward, J., \& Winstanley, D. (2005). Coming out at work: Performativity and the recognition and renegotiation of identity. The Sociological Review, 53(3), 447-475.

Worrall, L., Harris, K., Stewart, R., Thomas, A., \& McDermott, P. (2010). Barriers to women in the UK construction industry. Engineering, Construction and Architectural Management. http://doi.org/10.1108/09699981011038060

Wright, T. (2011). A "lesbian advantage"?: Analysing the intersections of gender, sexuality and class in male-dominated work. Equality, Diversity and Inclusion: An International Journal, 30(8),

Wright, T. (2013). Uncovering sexuality and gender: an intersectional examination of women's experience in UK construction. Construction Management and Economics, 31(January 2015), 832-844. http://doi.org/10.1080/01446193.2013.794297

Wright, T. (2016). Gender and Sexuality in Male-Dominated Occupations: Women Working in Construction and Transport. London: Palgrave MacMillan.

Wright, T., Colgan, F., Creegany, C., \& McKearney, A. (2006). Lesbian, gay and bisexual workers: equality, diversity and inclusion in the workplace. Equal Opportunities International, 25(6), 465-470. 